\title{
Levels of Selected Essential and Nonessential Metals in Roasted Coffee Beans of Yirgacheffe and Sidama, Ethiopia
}

\author{
A. Tesfay Gebretsadik ${ }^{1}$, Tarekegn Berhanu ${ }^{2}$, Belete Kefarge ${ }^{3}$ \\ ${ }^{1}$ Department of Industrial Chemistry, Addis Ababa Science and Technology University, Addis Ababa, Ethiopia \\ ${ }^{2}$ Strengthening of Agricultural Pesticide Residue Analysis System Project, JICA, Addis Ababa, Ethiopia \\ ${ }^{3}$ Department of Chemistry, Jigjiga University, College of Natural and Computational Science, Jigjiga, Ethiopia
}

Email address:

tgtesfageb@gmail.com (A. T. Gebretsadik)

\section{To cite this article:}

A. Tesfay Gebretsadik, Tarekegn Berhanu, Belete Kefarge. Levels of Selected Essential and Nonessential Metals in Roasted Coffee Beans of Yirgacheffe and Sidama, Ethiopia. American Journal of Environmental Protection. Vol. 4, No. 4, 2015, pp. 188-192.

doi: 10.11648/j.ajep.20150404.13

\begin{abstract}
The study was conducted to assess the contents of essential and non-essential metals in coffee beans. For this matter, seven essential metals such as $\mathrm{K}, \mathrm{Mg}, \mathrm{Ca}, \mathrm{Na}, \mathrm{Mn}, \mathrm{Cu}$ and $\mathrm{Zn}$ and two nonessential metals $(\mathrm{Cd}$ and $\mathrm{Pb})$ in four roasted coffee samples (washed Yirgacheffe, unwashed Yirgacheffe, washed Sidama and unwashed Sidama) were determined by FAAS. Closed microwave assisted wet digestion method with addition of concentrated $(69-70 \%) \mathrm{HNO}_{3}$ and $30 \% \mathrm{H}_{2} \mathrm{O}_{2}$ were selected for decomposition of ground roasted coffee samples. Generally, the levels of metals in all roasted coffee samples were found: $\mathrm{K}>\mathrm{Mg}>\mathrm{Ca}>\mathrm{Na}>\mathrm{Mn}>\mathrm{Zn}>\mathrm{Cu}$, but the non-essential metals $\mathrm{Pb}$ and $\mathrm{Cd}$ were found to be below method detection limit. The digestion method was evaluated by spiking roasted coffee samples and their percentage recoveries were in the range of 95 $-104 \%$. It is suggested that the consumption of roasted coffee beans could be a source of dietary essential metals and a possible entrance path way for trace metals to the food chain.
\end{abstract}

Keywords: Essential and Non-essential Metals, FAAS, Micro-wave Digestion, Roasted Coffee Beans

\section{Introduction}

Currently, one of the greatest challenges is the production of food, not only in sufficient amounts, but also with adequate nutritional quality, assuring nutritional balanced and a contaminant free food supply. Moreover, the increasing awareness of the important role of trace elements in biological systems has stimulated the extension and refinement of studies in this field which have provided a great deal of information. Accordingly, the content of mineral micronutrients and some other trace elements in coffee beans is of great general and special interest [1].

Over two-thirds of all the research literature on geographic origin commodities involves the analysis of vitamins or other organic molecules (amino acids, triglycerides, volatile aromatic compounds, etc.) [2]. However, a shortcoming of using vitamins (or other organic compounds) is their susceptibility to degradation those organic chemicals including enzymatic changes from the time of harvest through storage to the time of analysis [3]. This is also important because coffee beans are processed and organic chemical profiles are likely to be especially susceptible. The use of minerals and trace elements is therefore powerful because trace elements are significantly more stable in the commodity versus vitamins or some other types of organic compounds [4].

For determination of metals in raw or roasted coffees have used different analytical techniques like flame atomic absorption spectrometry (FAAS) [5], inductively coupled plasma optical emission spectrometry (ICP OES) [6] and neutron activation analysis (NAA) [7], results of these studies have revealed that the levels of metals differs among coffee species and varieties growing in the different parts of the world $[8,9]$. This study aimed to determine the levels of essential and non-essential metals in washed and unwashed Yirgacheffe and Sidama roasted coffee beans which grow in Ethiopia.

\section{Experimental}

\subsection{Instruments and Apparatus}

Coffee Roasting Machine (PROBAT-WERKE, BRZ-2 type 
Emmerich am Rhein, 2006, Germany), Microwave oven (Buck Scientific, inc. Type MWS-1, East Norwalk, USA) equipped with digestion vessels made of Teflon Fluor Modified (TFM), Flame atomic absorption spectrophotometer (FAAS) (Buck Scientific Model 210VGP AAS, East Norwalk, USA) fitted with deuterium background corrector and air acetylene flame atomizer.

\subsection{Chemicals and Reagents}

All the chemicals used were of analytical grade: 69-70\% $\mathrm{HNO}_{3}$ (Uni-Chem ${ }^{\mathrm{R}}$, Chemical reagents.), 30\% $\mathrm{H}_{2} \mathrm{O}_{2}$ (Uni$\mathrm{Chem}^{\mathrm{R}}$, Chemical reagents.), Lanthanum nitrate hydrate, 99.9\% (Aldrich, USA), Stock standard solutions of concentration $1000 \mathrm{mg} / \mathrm{L}$ in $2 \% \mathrm{HNO}_{3}$ of the metals $\mathrm{K}, \mathrm{Mg}$, $\mathrm{Ca}, \mathrm{Na}, \mathrm{Mn}, \mathrm{Zn}, \mathrm{Cu}, \mathrm{Cd}$ and $\mathrm{Pb}$ (Inorganic ${ }^{\mathrm{TM}}$ Ventures.) and Deionized water chemically pure with $<1.5 \mu \mathrm{s} / \mathrm{cm}$.

\subsection{Sample Preparation}

Both washed and unwashed coffee samples were collected using plastic bags from Ethiopia Commodity Exchange (ECX, Hawassa, Ethiopia) and Yirgacheffe Woreda marketing and cooperative bureau. The pre-treated (cleaned) green or raw coffee bean samples were roasted in $150 \mathrm{~g}$ batches by using coffee roasting machine (PROBAT-WERKE, BRZ-2 type Emmerich am Rhein, 2006, Germany) at the Ethiopian Commercial Exchange (ECX, Hawassa, Ethiopia) Coffee Quality and Flavor Inspection laboratory Center. All the roasting process was carried out by an expert on coffee roasting and the temperature and time needed for roasting of all coffee samples were $180{ }^{\circ} \mathrm{C}$ and 8-12 min respectively, medium roasting was selected among the degree of roasting coffee beans (light, medium and dark). Finally the roasted coffee samples were ground in to fine powder using mortar and pestle (to protect metal contamination).

\subsection{Digestion of Ground Roasted Coffee Samples}

In this study a method developed by Oleszczuket al. [14] with a mass of $0.3 \mathrm{~g}$ powder of each roasted coffee sample was transferred to TFM digestion vessels followed by addition of $5 \mathrm{~mL}$ of concentrated (69-70\%) $\mathrm{HNO}_{3}$ and $3 \mathrm{~mL}$ of $30 \% \mathrm{H}_{2} \mathrm{O}_{2}$ was selected for decomposition of ground roasted coffee samples. In the first step the temperature was linearly increased to $145{ }^{\circ} \mathrm{C}$ in $5 \mathrm{~min}$ with power of the rotating $80 \mathrm{~W}$. In the second step the temperature was kept $200{ }^{\circ} \mathrm{C}$ for $10 \mathrm{~min}$ with power of the rotating $90 \mathrm{~W}$ and in the third step the temperature was linearly decreased to $50{ }^{\circ} \mathrm{C}$ in $10 \mathrm{~min}$ with rotating power of $0 \mathrm{~W}$. For digestion of blank samples, eight reagent blanks were digested following the same procedure used for the ground roasted coffee samples. Finally, the concentrations of metals (K, $\mathrm{Na}, \mathrm{Ca}, \mathrm{Mg}, \mathrm{Mn}, \mathrm{Cu}$, $\mathrm{Zn}, \mathrm{Cd}$ and $\mathrm{Pd}$ ) were determined directly in the extract solution by flame atomic absorption spectrometry (FAAS).

\subsection{Digestion the Spiked Roasted Coffee Samples}

A spiking experiment was done to evaluate the efficiency and accuracy of the the method used. Known amounts of standard metal solutions were added to the roasted coffee samples taking care of the dilution of the final solution. Aliquots of $0.75 \mathrm{~mL}$ of $1000 \mathrm{mg} / \mathrm{L} \mathrm{K}, 0.75 \mathrm{~mL}$ of $100 \mathrm{mg} / \mathrm{L}$ $\mathrm{Mg}, \mathrm{Ca}$ and $\mathrm{Na}$ and $0.3 \mathrm{~mL}$ of $10 \mathrm{mg} / \mathrm{L} \mathrm{Mn}, \mathrm{Zn}, \mathrm{Cu}, \mathrm{Pb}$ and $\mathrm{Cd}$ were spiked at once in to a $0.3 \mathrm{~g}$ of ground roasted coffee samples in the TFM digestion vessel and digested following the same optimized procedure as the unspiked samples.

\subsection{Statistical Analysis}

The significance of variation between samples was analyzed by student's t-test and one-way ANOVA using Microsoft Excel (Microsoft Excel 13.0 Work Sheet, The Apache Software Foundation, 2007) was used.

\section{Results and Discussions}

\subsection{Method Validation}

The method detection limit for the metals in roasted coffee samples (Table 1) were calculated as as given below in equation 1 :

$$
M D L=t(n-1,1-\mu=0.99)(5)
$$

Where: $\mathrm{MDL}=$ method detection limit $\mathrm{t}(\mathrm{n}-1,1-\mu=0.99)=$ students' $t$ value appropriate for a $99 \%$ confidence level with $\left(\mathrm{t}_{7}=2.99\right.$, for $\left.\mathrm{n}=8\right) \mathrm{S}=$ standard deviation estimate with $\mathrm{n}-1$ degrees of freedom (for $n=8$ ).

Table 1. Method detection limit (MDL) for roasted coffee bean samples.

\begin{tabular}{llllllllll}
\hline Elements & $\mathbf{K}$ & $\mathbf{M g}$ & $\mathbf{C a}$ & $\mathbf{N a}$ & $\mathbf{M n}$ & $\mathbf{Z n}$ & $\mathbf{C u}$ & $\mathbf{C d}$ & $\mathbf{P d}$ \\
\hline $\operatorname{MDL}\left(\mu \mathrm{gg}^{-1}\right)$ & 0.07 & 0.05 & 0.04 & 0.06 & 0.02 & 0.03 & 0.02 & 0.01 & 0.04 \\
\hline
\end{tabular}

The percentage recoveries were calculated using equation 2 given below.

$$
R(\%)=\frac{\text { metalconcingpirked sample }- \text { metal concin unspicked sample }}{\text { Conc of metal spiked }} x 100
$$

The percentage recoveries of metals in the spiked roasted coffee samples were found in the range of $95 \%-104 \%$ with RSD $3-6 \%$ indicated in Table 2. 
Table 2. Recovery test results for the analysis of metals in roasted coffee samples.

\begin{tabular}{|c|c|c|c|c|}
\hline Element & Concentration in the sample $\left(\mu \mathrm{gg}^{-1}\right)^{\mathrm{a}}$ & Amount added $\left(\mu g^{-1}\right)$ & Concentration in the spiked sample $\left(\mu \mathrm{gg}^{-1}\right)^{\mathrm{b}}$ & Recovery (\%) \\
\hline $\mathrm{K}$ & 18563 & 2500 & $21013 \pm 21$ & $98 \pm 6$ \\
\hline $\mathrm{Mg}$ & 1992 & 250 & $2234 \pm 19$ & $97 \pm 4$ \\
\hline $\mathrm{Ca}$ & 965 & 250 & $1213 \pm 12$ & $95 \pm 3$ \\
\hline $\mathrm{Na}$ & 446 & 250 & $706 \pm 20$ & $104 \pm 6$ \\
\hline $\mathrm{Mn}$ & 19 & 10 & $29 \pm 0.8$ & $96 \pm 5$ \\
\hline $\mathrm{Zn}$ & 16 & 10 & $26 \pm 0.6$ & $103 \pm 4$ \\
\hline $\mathrm{Cu}$ & 10 & 10 & $21 \pm 0.5$ & $101 \pm 3$ \\
\hline $\mathrm{Cd}$ & ND & 10 & $10.3 \pm 0.3$ & $103 \pm 4$ \\
\hline $\mathrm{Pb}$ & ND & 10 & $10.2 \pm 0.2$ & $102 \pm 5$ \\
\hline
\end{tabular}

${ }^{\mathrm{a}}$ Mean concentration of samples, ${ }^{\mathrm{b}}$ Mean concentration $\pm \mathrm{SD}$ of spiked samples, ${ }^{\mathrm{c}} \mathrm{Mean}$ recovery $\pm \mathrm{SD}$ of percentage recoveries, $\mathrm{ND}=\mathrm{Not}$ detected

\subsection{Distribution of Metals in Roasted Coffee Samples}

The concentrations of macro-elements $(\mathrm{K}, \mathrm{Mg}, \mathrm{Ca}$ and $\mathrm{Na})$, micro-elements ( $\mathrm{Mn}, \mathrm{Cu}$ and $\mathrm{Zn}$ ) and non-essential elements $(\mathrm{Cd}$ and $\mathrm{Pb})$ determined in four types of roasted coffee samples summarized in Table 3.
Generally, the mean concentration of metals in all roasted coffee samples follows the order: $\mathrm{K}>\mathrm{Mg}>\mathrm{Ca}>\mathrm{Na}>\mathrm{Mn}>$ $\mathrm{Zn}>\mathrm{Cu}$, but the non-essential metals $\mathrm{Pb}$ and $\mathrm{Cd}$ were found to be below detection limit.

Table 3. Concentration (mean $\pm S D, n=3, \mu g g^{-1}$ ) of elements in the roasted coffee samples.

\begin{tabular}{|c|c|c|c|c|}
\hline \multirow[b]{2}{*}{ Element } & \multicolumn{4}{|c|}{ Concentration of metals ( $\mu g g-1) a$} \\
\hline & $\begin{array}{l}\text { Washed Yirgacheffe roasted } \\
\text { coffee }\end{array}$ & $\begin{array}{l}\text { Unwashed Yirgacheffe roasted } \\
\text { coffee }\end{array}$ & Washed Sidama roasted coffee & $\begin{array}{l}\text { Unwashed Sidama roasted } \\
\text { coffee }\end{array}$ \\
\hline K & $19610 \pm 343$ & $19471 \pm 392$ & $18754 \pm 462$ & $18563 \pm 477$ \\
\hline $\mathrm{Mg}$ & $1970 \pm 41$ & $1943 \pm 45$ & $2030 \pm 98$ & $1992 \pm 93$ \\
\hline $\mathrm{Ca}$ & $943 \pm 29$ & $931 \pm 17$ & $1009 \pm 18$ & $976 \pm 24$ \\
\hline $\mathrm{Na}$ & $484 \pm 85$ & $463 \pm 69$ & $475 \pm 65$ & $446 \pm 73$ \\
\hline $\mathrm{Mn}$ & $23 \pm 0.5$ & $21 \pm 0.3$ & $20 \pm 0.1$ & $19 \pm 0.2$ \\
\hline $\mathrm{Zn}$ & $14 \pm 0.3$ & $15 \pm 0.2$ & $17 \pm 0.2$ & $18 \pm 0.3$ \\
\hline $\mathrm{Cu}$ & $12 \pm 0.3$ & $13 \pm 0.2$ & $9 \pm 0.3$ & $10 \pm 0.1$ \\
\hline $\mathrm{Cd}$ & ND & ND & ND & ND \\
\hline $\mathrm{Pb}$ & ND & ND & ND & ND \\
\hline
\end{tabular}

${ }^{\mathrm{a}}$ Mean concentration \pm standard deviation of each sample analysed.

Washed Yirgacheffe roasted coffee: contains $\mathrm{K}$ in highest amount of the macro-elements with concentration $19610 \pm 343$ $\mu \mathrm{gg}^{-1}$ followed by $\mathrm{Mg}\left(1970 \pm 41 \mu \mathrm{gg}^{-1}\right)$ and $\mathrm{Ca}\left(943 \pm 29 \mu \mathrm{gg}^{-1}\right)$. $\mathrm{Na}\left(484 \pm 85 \mu \mathrm{gg}^{-1}\right)$ was found to be present at the lowest concentration of the macro-elements analyzed (Table 3). Among the concentration of trace micro-elements, Mn $\left(23 \pm 0.5 \mathrm{\mu g}^{-1}\right)$ was found in higher amount than others followed by $\mathrm{Zn}\left(14 \pm 0.3 \mu \mathrm{gg}^{-1}\right)$ and $\mathrm{Cu}\left(12 \pm 0.3 \mu \mathrm{gg}^{-1}\right)$.

Unwashed Yirgacheffe roasted coffee: of the macroelements K with concentration $19471 \pm 392 \mu \mathrm{gg}^{-1}$ was found to be present in the highest level followed by $\mathrm{Mg}(1943 \pm 45$ $\left.\mu \mathrm{gg}^{-1}\right), \mathrm{Ca}\left(931 \pm 17 \mu \mathrm{gg}^{-1}\right)$ and $\mathrm{Na}\left(463 \pm 69 \mu \mathrm{gg}^{-1}\right)$ with the lowest concentration of the macro-elements analyzed (Table 3). Unwashed Yirgacheffe roasted coffee type also contains, Mn with concentration $21 \pm 0.3 \mu \mathrm{gg}^{-1}$ followed by $\mathrm{Zn}(15 \pm 0.2$ $\left.\mu \mathrm{gg}^{-1}\right)$ and $\mathrm{Cu}\left(13 \pm 0.2 \mu \mathrm{gg}^{-1}\right)$.

Washed Sidama roasted coffee: among the macro-elements, $\mathrm{K}$ was found in highest amount with concentration $18754 \pm 462 \mu \mathrm{gg}^{-1}$ than $\mathrm{Mg}\left(2030 \pm 98 \mu \mathrm{gg}^{-1}\right)$ and $\mathrm{Ca}(1009 \pm 18$ $\left.\mu \mathrm{gg}^{-1}\right)$. Na with concentration $475 \pm 65 \mu \mathrm{gg}^{-1}$ was found to be present at the lowest concentration of the macro-elements analyzed (Table 3). Washed Sidama roasted coffee also contains $\mathrm{Mn}$ with concentration $20 \pm 0.1 \mu \mathrm{gg}^{-1}, \mathrm{Zn}(17 \pm 0.2$ $\left.\mu \mathrm{gg}^{-1}\right)$ and $\mathrm{Cu}\left(9 \pm 0.3 \mu \mathrm{gg}^{-1}\right)$ slightly lower than the micro- elements.

Unwashed Sidama roasted coffee: the fourth which is washed Sidama roasted coffee type also contains $\mathrm{K}$ with concentration $18563 \pm 477{\mu \mathrm{gg}^{-1}}^{-1}$ in the highest level followed by $\mathrm{Mg}\left(1992 \pm 93 \mu \mathrm{gg}^{-1}\right), \mathrm{Ca}\left(976 \pm 24 \mu \mathrm{gg}^{-1}\right)$ and $\mathrm{Na}(446 \pm 73$ $\left.\mu \mathrm{gg}^{-1}\right)$ with the lowest concentration of the macro-elements analyzed (Table 3 ). In this roasted coffee sample Mn with concentration $19 \pm 0.2 \mu \mathrm{gg}^{-1}, \mathrm{Zn}\left(18 \pm 0.3 \mu \mathrm{gg}^{-1}\right)$ and $\mathrm{Cu}$ $\left(10 \pm 0.1 \mu^{-1}\right)$ slightly lower than the microelements.

\subsection{Statistical Analysis}

The significance of variation in metals concentration between samples was analysed by students t-test and oneway ANOVA. Accordingly, students' t-test shows, for concentration of; $\mathrm{K}, \mathrm{Mg}, \mathrm{Ca}$ and $\mathrm{Na}$ no significant difference at $\mathrm{p}=0.05$ and for concentrations of; $\mathrm{Mn}, \mathrm{Zn}$ and $\mathrm{Cu}$ a significant difference at $p=0.05$ was observed between washed and unwashed Yirgacheffe as well as between washed and unwashed Sidama roasted coffee samples respectively.

From one way ANOVA test for significant difference; for concentrations of $\mathrm{Mg}$ and $\mathrm{Na}$ no significant difference at $\mathrm{p}=$ 0.05 and for $\mathrm{Mn}, \mathrm{Zn}$ and $\mathrm{Cu}$, a significant difference at $\mathrm{p}=$ 0.05 was observed between all four roasted coffee samples. 
However, for concentrations of $\mathrm{K}$ and $\mathrm{Ca}$; a significant difference at $\mathrm{p}=0.05$ was observed only for both washed Yirgacheffe and Sidama as well as for both unwashed Yirgacheffe and Sidama roasted coffee samples respectively.

\subsection{Comparison of the Metal Content of Roasted Coffee Samples with Other Reported Values}

In different studies the metal content of roasted coffee samples have been analyzed for both Arabica and Robusta coffee types [9-11]. The composition of $\mathrm{Ba}, \mathrm{Ca}, \mathrm{Cu}, \mathrm{Fe}, \mathrm{K}$, $\mathrm{Mg}, \mathrm{Mn}, \mathrm{Na}, \mathrm{P}, \mathrm{Sr}$ and $\mathrm{Zn}$ have been determined and used as chemical descriptions to differentiate between roasted coffee samples from Arabica and Robusta coffee varieties. According to the report on roasted coffee varieties present in southeast Brazilian market, there is a difference in metal content among the samples of roasted coffee varieties. These variations in metal compositions among samples roasted coffee can indicate the differences in the factors that influence the cultivation of the coffee plant; such as the type of soil, the use of fertilizers with different chemical compositions and the ambient conditions [9].

Although various chemical analyses target to a similar objective, there may also be a difference in sampling, sample preparation and analytical techniques. Considering all these, the result of the present study can be compared to the findings of other authors. Martin et al.[11] have determined the metal content of roasted coffee samples of various origin and the concentrations have been used as chemical descriptors to differentiate between roasted coffee samples from the Arabica and Robusta varieties. The Arabica coffee variety from Nicaragua contained $\left(\mu \mathrm{gg}^{-1}\right)$ : $\mathrm{Ca}$ (970), $\mathrm{Cu}$ (13.4), Fe (46.2), K (14930), Mg (1740), Mn (14.1), Na (33.4) and $\mathrm{Zn} \mathrm{(19.3)} \mathrm{while} \mathrm{the} \mathrm{Robusta} \mathrm{variety} \mathrm{from} \mathrm{Ivory} \mathrm{Cost}$ contained Ca (940), Cu (16.1), Fe (56.1), K (14480), Mg (1610), Mn (12.2), $\mathrm{Na}$ (21.4) and $\mathrm{Zn}$ (13.9) comparable to the values reported in this paper. Furthermore, they used the P, $\mathrm{Mn}$ and $\mathrm{Cu}$ content to discriminate between the Arabica and Robusta roasted coffee varieties. Ashu and Chandravanshi [13] also determine the concentrations of metals $(\mathrm{K}, \mathrm{Mg}, \mathrm{Ca}$, $\mathrm{Na}, \mathrm{Mn}, \mathrm{Fe}, \mathrm{Cu}, \mathrm{Zn}, \mathrm{Co}, \mathrm{Pb}, \mathrm{Cd}$ ) in three brands of commercially available roasted Ethiopian coffee powders (Abyssinia, Alem and Pride). The mean concentration of each metal in the three brands of coffee powder samples was ( $\mu \mathrm{gg}^{-}$

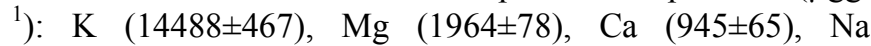
(484 \pm 12$), \mathrm{Fe}(52.0 \pm 4.0), \mathrm{Mn}(23.0 \pm 0.9), \mathrm{Cu}(14.0 \pm 0.6), \mathrm{Zn}$ $(15.0 \pm 0.8)$ and $\mathrm{Co}(1.60 \pm 0.05)$ in which both those results are comparable with the present study.

The results of the present study are in good agreement with the most of reported values. Moreover, the general trend of the metal concentration for macro-elements $\mathrm{K}>\mathrm{Mg}>\mathrm{Ca}>$ $\mathrm{Na}$ is in good agreements. Regarding the trace microelements, $\mathrm{Mn}>\mathrm{Zn}>\mathrm{Cu}>\mathrm{Co}$ in roasted coffee powder is followed for most reports. Similarly, reports by Ashu and Chandravanshi [13] and Grembecka et al. [16-17] shows that toxic elements $\mathrm{Pb}$ and $\mathrm{Cd}$ were not detectable under their analysis conditions using the FAAS which is in a good agreement with the present study. Generally, the concentration of the macro and micro-elements in both washed and unwashed Yirgacheffe and Sidama roasted coffee samples (present study) were compared to other reported values in Table 4 and 5.

Table 4. Comparison of the concentrations of macro-elements in roasted coffee beans samples with other reported values.

\begin{tabular}{|c|c|c|c|c|c|}
\hline \multirow{2}{*}{ Origin } & \multicolumn{4}{|c|}{ Concentration $\left(\mu \mathrm{gg}^{-1}\right)$ of metal in roasted coffee beans } & \multirow{2}{*}{ Reference } \\
\hline & $\mathbf{K}$ & Mg & $\mathbf{C a}$ & $\mathrm{Na}$ & \\
\hline Ethiopia & $18563-19610$ & $1943-2030$ & $931-1009$ & $446-484$ & Present study \\
\hline Various origins & $11750-15850$ & $800-2840$ & $513-1620$ & $382-459$ & {$[16]$} \\
\hline Brazil & $32500-39800$ & $2120-4150$ & $1110-1890$ & $274-665$ & {$[10]$} \\
\hline Ivory Coast & $14010-14480$ & $1610-1820$ & $940-1220$ & $15.9-21.4$ & [11] \\
\hline Ethiopia & $14310-19400$ & $5470-6080$ & $500-990$ & - & {$[12]$} \\
\hline Ethiopia & $14361-14583$ & $1959-1968$ & $843-1045$ & $468-501$ & {$[13]$} \\
\hline
\end{tabular}

Table 5. Comparison of the concentrations micro-elements in the roasted coffee bean samples with literature values.

\begin{tabular}{|c|c|c|c|c|c|c|}
\hline \multirow{2}{*}{ Origin } & \multicolumn{5}{|c|}{ Concentration $\left(\mu \mathrm{gg}^{-1}\right)^{\mathrm{b}}$ of metal in roasted coffee beans } & \multirow{2}{*}{ Reference } \\
\hline & Mn & Zn & $\mathbf{C u}$ & Cd & $\mathbf{P b}$ & \\
\hline Ethiopia & $19-23$ & $14-18$ & $9-13$ & ND & ND & Present study \\
\hline Brazil & $29-40$ & $3.9-9.8$ & $49-88$ & $0.7-0.9$ & $0.015-0.058$ & {$[10]$} \\
\hline Ethiopia & $22-24$ & $12-19$ & $11-17$ & ND & ND & [13] \\
\hline Various origins & $16.5-40.6$ & $3.2-16.2$ & $12.1-20.1$ & ND & ND & [16] \\
\hline Ethiopia & $15-20$ & $6-30$ & $13-28$ & ND & ND & [12] \\
\hline
\end{tabular}

${ }^{\mathrm{b}}$ Their concentrations were below detection limit, ND $=$ Not detected

\section{Conclusions}

The closed microwave assisted wet digestion method and determination of selected metals in roasted coffee samples by flame atomic absorption spectroscopic method was found to be efficient. $\mathrm{K}$ has high concentration among the macroelements ( $\mathrm{Mg}, \mathrm{Na}$ and $\mathrm{Ca}$ ). Moreover, $\mathrm{Mn}$ found high level comparing with other micro-elements $(\mathrm{Mn}, \mathrm{Zn}$ and $\mathrm{Cu})$. In all roasted coffee bean samples the level of toxic elements $(\mathrm{Cd}$ and $\mathrm{Pb}$ ) were avail below the method detection limits. The 
levels of both essential and non-essential metals investigated in roasted coffee beans were comparable with that of the rest of the world. It could be suggested that the roasted coffee beans under investigation could be source of dietary minerals and trace metals and could be valuable in complementing available food composition data and estimating dietary intakes of essential and nonessential metals in Ethiopia through coffee consumption.

\section{Acknowledgments}

Ministry of Education (MOE) for financial support and Department of Chemistry, Hawassa University (Ethiopia) for providing the laboratory facilities are gratefully acknowledged.

\section{References}

[1] V. Krivan, P. Barth, A. Feria and M. Mikrochim (1993) Multielement Analysis of Green Coffee and Its Possible Use for the Determination of Origin. MikrochimicaActa 110: 217 236

[2] J. A. DeSousa (1996) Verifying wine origin: a neural network approach. American Journal of Enology and Viticulture 47: $410-414$

[3] F. Lavedrine, A. Ravel, A. Poupard, and J. Alary (1997) Effect of geographic origin, variety and storage on tocopherol concentrations in walnuts by HPLC. Food Chemistry 58:135140

[4] A. Kim, Anderson, and W. B. Smith (2002) Chemical Profiling To Differentiate Geographic Growing Origins of Coffee. Journal of Agriculture and Food Chemistry 50:2068-2075

[5] M. Grembecka, E. Malinowska and P. Szefer (2007) Differentiation of market coffee and its infusions in view of their mineral composition. Science of Total Environment 383:59-69

[6] R. J. Clarker and L. J. Walker (1974) Potassium and Other Mineral Contents of Green, Roasted and Instant Coffee. Journal of the Science of Food and Agriculture 25:1389-1404

[7] J. H. Zaidi, I. Fatima, M. Arif and I. H. Qureshi (2006) Determination of trace elements in coffee beans andinstant coffee of various origins by INAA.Journal of Radioanalytical and Nuclear Chemistry 267:109-112

[8] E. E. Santos, D. C. Lauria and C. L. Porto da Silveira (2004) Assessment of daily intake of trace elements due to consumption of foodstuffs by adult inhabitants of Rio de Janeiro city. Science of the Total Environment 327:69-79

[9] M. J. Martin, F. Pablos and A. G. Gonzalez (1998) Characterization of Green Coffee Varieties According to Their Metal Content. AnalyticaChimicaActa 358:177-183

[10] E. J. dos Santos and E. de Oliveira (2001) Determination of Mineral Nutrients and Toxic Elements in Brazilian Soluble Coffee by ICP -AES. Journal of food Composition and Analysis 14:523-531

[11] M. J. Martin, F. Pablos and A. G. Gonzalez (1999) Characterization of Arabica and Robusta Roasted Coffee Varieties and Mixture Resolution According to Their Metal Content. Food Chemistry 66:365-370

[12] A. Gure (2006) Investigation of Metals in Raw and Roasted Indigenous Coffee Varieties in Ethiopia. M.Sc. Project, Addis Ababa University, Addis Ababa, Ethiopia 1-53

[13] R. Ashu and B. S. Chandravanshi (2011) Concentration levels of metals in commercially available Ethiopian roasted coffee powders and their infusions. Bulletin of Chemical Society of Ethiopia 25:11-24

[14] N. Oleszczuk, J. T. Castro, M. M. da Silva, M. G. A. Korn, B. Welz, and M. G. R., Vale (2007) Method development for the determination of manganese, cobalt and copper in green coffee comparing direct solid sampling electrothermal atomic absorption spectrometry and inductively coupled plasma optical emission spectrometry. Talanta 73:862-869

[15] D. Perrone, C. M. Donangelo and A. Farah (2008) Fast simultaneous analysis of caffeine, trigonelline, nicotinic acid and sucrose in coffee by liquid chromatography-mass spectrometry. Food Chemistry 110:1030-1035

[16] M. Grembecka, E. Malinowska and P. Szefer (2007) Differentiation of market coffee and its infusions in view of their mineral composition. Science of Total Environment 383:59-69.

[17] J. B. Edward, E. O. Idowu, J. A. Oso, O. R. Ibidapo (2013) Determination of Heavy Metal Concentration in Fish Samples, Sediment and Water from Odo-Ayo River in AdoEkiti, Ekiti-State, Nigeria, International Journal of Environmental Monitoring and Analysis. 1:27-33 